\title{
Corrigendum: Towards strengthening collaboration between district and local municipalities in South Africa: Insights from Ehlanzeni District Municipality
}

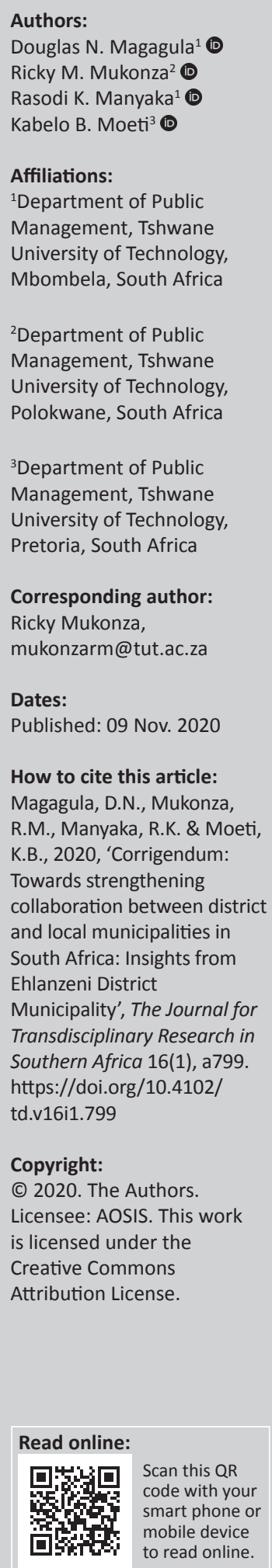

In the version of this article initially published, Magagula, D.N., Mukonza, R.M., Manyaka, R.K. \& Moeti, K.B., 2019, 'Towards strengthening collaboration between district and local municipalities in South Africa: Insights from Ehlanzeni District Municipality', The Journal for Transdisciplinary Research in Southern Africa 15(1), a673. https://doi.org/10.4102/td.v15i1.673, the organisation name 'Ehlanzeni District Municipality' was incorrectly abbreviated as EDMEDM in some instances throughout the article. The correct abbreviation should be EDM.

This correction does not alter the study's findings of significance or overall interpretation of the study's results. The authors apologise for any inconvenience caused. 